\title{
Plasma Enhanced Detection Of Methane On Pt/SnO Sensors At Low Temperatures
}

\author{
M. Arvari' ${ }^{1}$ A. A. Khodadadi², Y. Mortazavi² \\ 1Catalysis and Reaction Engineering Laboratory, Departmentt of Chemical Engineering, University of \\ Tehran, Tehran, Iran \\ 2 Nanoelectronics Centre of Excellence, University of Tehran, Tehran, Iran \\ khodadad@ut.ac.ir
}

\begin{abstract}
:
In this study, a non-thermal plasma (NTP) corona needle-shape reactor was applied before $\mathrm{Pt} / \mathrm{SnO} 2$ sensor to detect methane with high responses at low temperatures. 5000 ppm methane in air, by passing through NTP reactor at ambient temperature, have been converted to reactive intermediately including CO. After reaching to the sensor, the responses have been measured at $200-400^{\circ} \mathrm{C}$ temperature range. The effects of plasma parameters including the distance between electrodes and electrical power, as well as sensor temperature have been varied. The synthesis of $\mathrm{Pt} / \mathrm{SnO}_{2} \mathrm{was}$ carried out by precipitation method impregnated with $\mathrm{H}_{2} \mathrm{PtCl}_{6}$ to get $1.0 \mathrm{wt} \% \mathrm{Pt} / \mathrm{SnO}_{2}$. The sample was characterized by XRD, BET and FTIR. Exposure of methane to NTP reactor with $2.5 \mathrm{~mm}$ electrode distance by an increase in electrical power to $0.9 \mathrm{~W}$ results in $20 \%$ conversion. The corresponding parameters at $5 \mathrm{~mm}$ interval are $1.4 \mathrm{~W}$ and $41 \%$. Without using the plasma, maximum response to $\mathrm{CH}_{4}$ occurs at the high temperature of $400^{\circ} \mathrm{C}$. At electrode distances of $2.5 \mathrm{~mm}$ with $0.9 \mathrm{~W}$ electrical power and $5 \mathrm{~mm}$ with $1.4 \mathrm{~W}$, the maximum responses has increased 144 and 331 times respectively than the single sensor at $200^{\circ} \mathrm{C}$. This way, very high responses to $\mathrm{CH}_{4}$ at $200^{\circ} \mathrm{C}$ has been achieved by $\mathrm{Pt} / \mathrm{SnO}_{2}$ gas sensor in the presence of NTP corona needle system.
\end{abstract}

Key words: non-thermal plasma, corona, gas sensor, methane, CO

\section{Introduction}

For about thirty years, non-thermal plasma (NTP) technologies have been successfully implemented to combustion processes such as reforming of methane or natural gas to produce $\mathrm{H}_{2}$ and $\mathrm{CO}$ [1]. Providing required energy to produce reactive species (electron, radical and ions) is the main role of such a plasma results in boosting fuel reforming reactions [2]. Detection of methane as one of the pollutant and the main component of natural gas for domestic and industrial uses is indispensable [3]. As reported in litteratures among most dopants and catalysts, the platinum group metal ( $\mathrm{Pt}$ and $\mathrm{Pd}$ ) are mainly utilized for enhancing the selectivity and sensing response especially to methane [4]. In this study, Because $\mathrm{Pt} / \mathrm{SnO}_{2}$ sensors have high response to detect $\mathrm{CH}_{4}$ gas at high temperatures and contrary to it for $\mathrm{CO}$ at low temperatures, an NTP system is introduced to obtain a high response to methane at lower temperatures by converting methane into carbon monoxide.

\section{Experimental}

$\mathrm{SnO}_{2}$ nanostructures were synthesized by a precipitaion method. Anhydrous stannic tetrachloride has been dissolved in de-ionized water and precipitated by ammonia solution.

The precipitate were centrifuged and washed with deionized water several times and dried at $80^{\circ} \mathrm{C}$ for $12 \mathrm{~h}$. The obtained powder has been calcined at $500^{\circ} \mathrm{C}$ for $4 \mathrm{~h}$. To obtain $1.0 \mathrm{wt}$. \% $\mathrm{Pt} / \mathrm{SnO}_{2}, \mathrm{H}_{2} \mathrm{PtCl}_{6}$ has been impregnated onto the $\mathrm{SnO}_{2}$ powder, followed by drying at $80^{\circ} \mathrm{C}$ and calcining at $500^{\circ} \mathrm{C}$ for $4 \mathrm{~h}\left(\mathrm{Pt} / \mathrm{SnO}_{2}\right)$. A corona reactor including two needle type electrodes (platinum wire of $100 \mu \mathrm{m}$ ID) in a micro reactor connected to a high voltage DC power supply.

\section{Results}

The BET surface area of $\mathrm{Pt} / \mathrm{SnO}_{2}$ is $70 \mathrm{~m}^{2} / \mathrm{g}$. Figure 1 shows The XRD patterns of the tetragonal phase with cassiterite structure of $\mathrm{SnO}_{2}$. Sensor response to $\mathrm{CH}_{4}$ with a concentration of 5000 ppm and a flow of $50 \mathrm{ml} /$ min without the presence of plasma has risen 
from 1.4 to 19 with an increase in temperature from $200{ }^{\circ} \mathrm{C}$ to $400{ }^{\circ} \mathrm{C}$ (see Fig. 2).

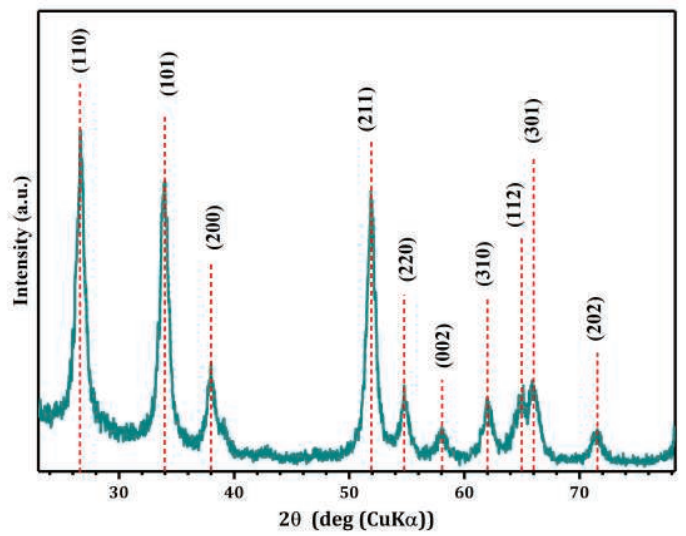

Fig. 1. The XRD patterns of $\mathrm{Pt} / \mathrm{SnO}_{2}$

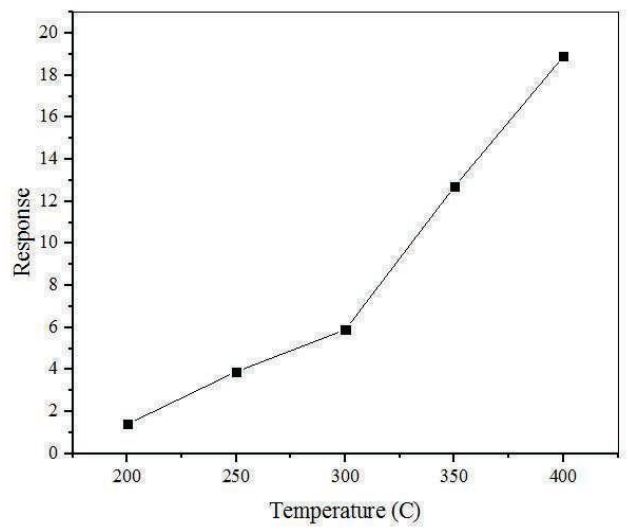

Fig. 2. $\mathrm{Pt} / \mathrm{SnO} \mathrm{O}_{2}$ sensor response to $5000 \mathrm{ppm} \mathrm{CH}_{4}$ at different temperatures without using NTP system.

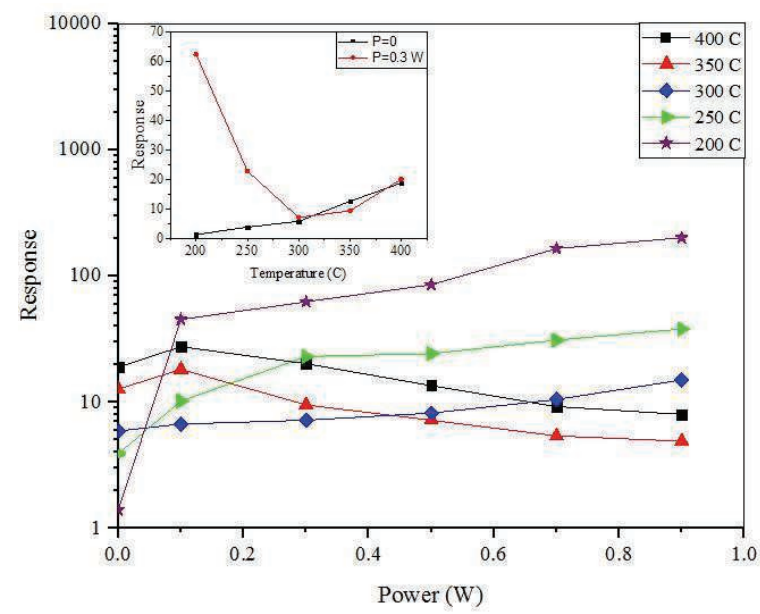

Fig. 3. $\mathrm{Pt} / \mathrm{SnO} \mathrm{O}_{2}$ sensor response to $5000 \mathrm{ppm} \mathrm{CH}_{4}$ at different temperatures in the presence of NTP system with various electrical power at the electrode distance of $2.5 \mathrm{~mm}$

\section{Conclusion}

$\mathrm{CH}_{4}$ converts to reactive intermediates such as $\mathrm{CO}$ by the needle-shaped corona plasma. Sensor response to methane by changing the plasma electrical power at $5 \mathrm{~mm}$ and $2.5 \mathrm{~mm}$ electrode distances are shown in Fig. 4 and 5. With increasing corona power up to $0.9 \mathrm{~W}$ at $2.5 \mathrm{~mm}$ of electrodes distance, conversion reaches $20 \%$. At an interval of $5 \mathrm{~mm}$, the corresponding parameters are $1.4 \mathrm{~W}, 41 \%$. At the electrode distance of $2.5 \mathrm{~mm}$ with $0.9 \mathrm{~W}$ power the maximum response is 201 at $200^{\circ} \mathrm{C}$ that is 144 times higher than the sensor without applying NTP reactor. As the same way, for $5 \mathrm{~mm}$ interval with $1.4 \mathrm{~W}$, the maximum response is 463 at $200^{\circ} \mathrm{C}$ that is 331 and 2.3 times higher than single sensor and sensor along with NTP system of $2.5 \mathrm{~mm}$ interval model respectively.

This way, very high responses to $\mathrm{CH}_{4}$ at $200^{\circ} \mathrm{C}$ has been achieved by $\mathrm{Pt} / \mathrm{SnO}_{2}$ gas sensor in the presence of NTP corona needle system.

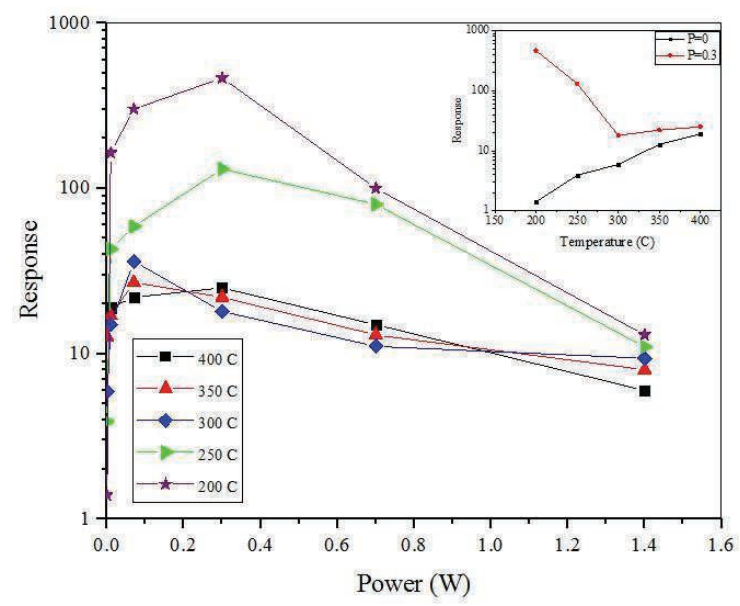

Fig. 4. $\mathrm{Pt} / \mathrm{SnO}_{2}$ sensor response to $5000 \mathrm{ppm} \mathrm{CH}_{4}$ at different temperatures in the presence of NTP system with various electrical power at the electrode distance of $5 \mathrm{~mm}$.

\section{References}

[1] J. Luche, O. Aubry, A. Khacef, J. Cormier, Syngas production from methane oxidation using a non-thermal plasma: Experiments and kinetic modeling, Chemical Engineering Journal 149 (2009) 35-41; doi: 10.1016/j.cej.2008.09.045

[2] J. D. Rolliet, J. Gonzalez-Aguilar, G. Petitpas†, A. Darmon, L. Fulcheri, R. Metkemeijer, Experimental Study on Gasoline Reforming Assisted by Nonthermal Arc Discharge, Energy Fuels, 2008, 22 (1), pp 556-560; doi: 10.1021/ef700540v

[3] S. Basu, P. Basu, Nanocrystalline metal oxides for methane sensors: role of noble metals, Journal of Sensors, 2009(2009); doi: $10.1155 / 2009 / 861968$

[4] W. Lu, D. Ding, Q. Xue, Y. Du, Y. J. Zhang, X. Pan, W. Xing, Great enhancement of $\mathrm{CH}_{4}$ sensitivity of $\mathrm{SnO}_{2}$ based nanofibers by heterogeneous sensitization and catalytic effect, Volume 254, Sensors and Actuators B: Chemical, 254 (2018) 393-401; doi: 10.1016/j.snb.2017.07.128 